\title{
Efeito da Fitase e Xilanase sobre o Desempenho e as Características Ósseas de Frangos de Corte Alimentados com Dietas Contendo Farelo de Arroz ${ }^{1}$
}

\author{
Ademir José Conte ${ }^{2}$, Antonio Soares Teixeira ${ }^{3}$, Elias Tadeu Fialho ${ }^{3}$, Neudi Artêmio Schoulten ${ }^{4}$, \\ Antônio Gilberto Bertechini ${ }^{3}$
}

\begin{abstract}
RESUMO - O presente trabalho foi conduzido com o objetivo de verificar o efeito do uso da fitase e xilanase no desempenho e na deposição óssea de minerais em frangos de corte alimentados com dietas contendo $15 \%$ de farelo de arroz, baixo fósforo disponível e sem suplementação de ferro, cobre, zinco e manganês. A fitase utilizada foi da marca comercial Natuphos 5000 e a xilanase, da marca Avizyme 1300. O delineamento experimental foi inteiramente casualizado, em esquema fatorial $4 \times 2+1$. A dieta controle foi composta por níveis adequados de nutrientes, sem farelo de arroz e sem enzimas. As dietas dos demais tratamentos foram formuladas com $15 \%$ de farelo de arroz, contendo baixo fósforo disponível (40\% do recomendado) e sem suplementação inorgânica de $\mathrm{Fe}, \mathrm{Cu}, \mathrm{Zn}$ e $\mathrm{Mn}$, com quatro níveis de fitase $(0,400,800$ e $1.200 \mathrm{FTU} / \mathrm{kg})$, com ou sem xilanase $(1 \mathrm{~kg} / \mathrm{t})$. As variáveis estudadas aos $21 \mathrm{e} 42$ dias de idade foram desempenho e cinzas, $\mathrm{P}, \mathrm{Zn}, \mathrm{Fe}$, Mn e Cu na tíbia. O peso vivo e consumo de ração aumentaram de maneira significativa com a adição de fitase, enquanto que a conversão alimentar não foi afetada, tanto aos 21 como aos 42 dias. O melhor nível de fitase foi de 1.105 e 1.023 FTU/kg para melhor desempenho, aos 21 e 42 dias de idade, respectivamente. A xilanase não afetou significativamente o peso vivo e o consumo de ração, porém melhorou significativamente a conversão alimentar nas duas idades avaliadas, em função de menor consumo de ração nas aves que receberam xilanase. Os níveis de fitase promoveram aumento linear nos teores de cinzas e fósforo da tíbia e não afetaram a deposição de $\mathrm{Zn}, \mathrm{Fe}, \mathrm{Mn}$ e $\mathrm{Cu}$, nas duas idades estudadas. A xilanase não afetou os parâmetros avaliados na tíbia.
\end{abstract}

Palavras-chave: desempenho, farelo de arroz, fitase, minerais, tíbia, xilanase

\section{Effect of Phytase and Xilanase on the Performance and Bone Characteristics of Broiler Chicks Fed Diets with Rice Bran}

\begin{abstract}
The present work was designed to verify the effect of the use of phytase and xylanase upon the performance and bone deposition of minerals in broiler diets containing $15 \%$ of rice bran, low available phosphorus and without supplementation of iron, zinc, copper and manganese. The phytase utilized was the Natuphos 5000 and the xylanase Avizyme 1300. The experimental design was the completely randomized and the analysis of variance in a $4 \times 2+1$ factorial scheme. The control diet was made up of adequate levels of all nutrients without rice bran and without enzymes. The diets of the other treatments were formulated with $15 \%$ of rice bran with low available phosphorus ( $40 \%$ of the recommended) and without inorganic supplementation of $\mathrm{Fe}, \mathrm{Cu}, \mathrm{Zn}$ and Mn with four levels of phytase (0, 400, 800 and 1,200 units $/ \mathrm{kg}$ ) with or without xylanase $(1 \mathrm{~kg} / \mathrm{t})$. The variables analyzed at 21 and 42 days of age were performance and ash, $\mathrm{P}$, $\mathrm{Zn}, \mathrm{Fe}, \mathrm{Mn}$ and $\mathrm{Cu}$ in the tibia. Live weight and feed intake increased significantly with supplementation of phytase whereas feed conversion was not affected both at 21 and 42 days. The best level of phytase of 1.105 and $1.023 \mathrm{FTU} / \mathrm{kg}$ for better performance was reached at 21 and 42 days, respectively. The xylanase did not affect significantly live weight and feed intake. Therefore the data shown a significant improvement in feed conversion at the two ages evaluated provided by lower feed intake by the birds fed diets supplemented with xylanase. The phytase levels shown a linear increase in the contents of ash and phosphorus in the tibia and did not affect the deposition of $\mathrm{Zn}$, Fe, $\mathrm{Mn}$ and $\mathrm{Cu}$ in the two studied ages. The xylanase did not have any effect on the parameters evaluated in the tibia.
\end{abstract}

Key Words: performance, phytase, minerals, rice bran, tibia, xylanase

\section{Introdução}

O farelo de arroz integral (FAI), embora rico em alguns nutrientes, tem sua utilização limitada na alimentação de aves, devido à presença de fatores antinutricionais. Entre estes, podem-se citar os altos teores de ácido fítico e de polissacarídeos não amídicos (PNA).

A presença do ácido fítico mantém complexado aproximadamente $85 \%$ do fósforo, segundo Rostagno (1998). Além do fósforo, outros minerais podem ligar-se a esta molécula, principalmente cátions

\footnotetext{
1 Parte da Tese de Doutorado do primeiro autor, apresentada ao Departamento de Zootecnia da UFLA.

2 Doutorado em Nutrição de Monogástricos, DZO/UFLA. Professor da E.A.F. Cuiabá-MT- BR 364, Km 329, CEP: 78.106-000, Cuiabá-MT. E.mail: ajconte@vsp.com.br

${ }^{3}$ Professores do Departamento de Zootecnia da Universidade Federal de Lavras, Caixa postal 37, CEP: 37.200-000, Lavras-MG.

${ }^{4}$ Estudante de Doutorado do Departamento de Zootecnia da UFLA.
} 
divalentes, reduzindo a sua disponibilidade para o animal. Vohara et al., citados por Pearson et al. (1998), demonstraram o potencial de complexação de diversos minerais à molécula de fitato, na seguinte ordem: cobre $>$ zinco $>$ níquel $>$ cobalto $>$ manganês $>$ ferro $>$ cálcio.

Os polissacarídeos não amiláceos, ou simplesmente fibras, principais constituintes da parede celular dos alimentos de origem vegetal, não podem ser digeridos pelas aves, devido à natureza de suas ligações, sendo resistentes à hidrólise no trato digestivo. A dificuldade na digestão da fibra, além de reduzir a energia do alimento, pode prejudicar a utilização do todos os outros nutrientes. Isto ocorre principalmente quando o tipo de fibra do alimento é solúvel, ou seja, tem grande capacidade de absorver água e formar substância gelatinosa no trato intestinal. A fibra solúvel é composta principalmente pela hemicelulose, a qual é composta, principalmente, pelos $\beta$-glucanos na cevada e aveia e arabinoxilanos no trigo, centeio e farelo de arroz.

A enzima fitase, produzida comercialmente por microorganismos do gênero Aspergillus, tem sido utilizada com sucesso nas rações de suínos e aves para aumentar a disponibilidade do fósforo complexado na molécula de fitato. Além disso, a sua utilização tem possibilitado aumento na disponibilidade de outros minerais, embora estes resultados ainda sejam controversos.

As enzimas carboidrases, entre elas a xilanase e a glucanase, também produzidas por fungos do gênero Aspergillus, têm sido usadas para hidrolisar os polissacarídeos não amiláceos, aumentando a digestibilidade de alimentos como a cevada, o trigo, o centeio, a aveia e o triticale.

A utilização combinada de duas enzimas, a fitase e a xilanase, pode tornar o farelo de arroz uma excelente alternativa de alimentação para as aves, inclusive como ótima fonte de fósforo, já que os principais fatores antinutritivos presentes no farelo de arroz são o alto teor de fibra e fitato.

Assim, o objetivo do presente trabalho foi determinar o efeito do uso das enzimas fitase e xilanase no desempenho e deposição óssea de minerais em frangos de corte alimentados com dietas contendo $15 \%$ de farelo de arroz, baixo fósforo disponível e sem suplementação inorgânica de ferro, cobre, zinco e manganês.

\section{Material e Métodos}

Utilizaram-se, neste experimento, 900 pintos de corte de 1 dia de idade, da linhagem Ross, sexados, vacinados contra a doença de Marek, com peso médio inicial de $43 \mathrm{~g}$. Foram alojados 25 pintos do mesmo sexo em cada parcela experimental. O manejo diário das aves no decorrer de toda a fase experimental seguiu as recomendações técnicas de criação, conforme manual de manejo de criação da linhagem Ross. Água e ração experimental foram fornecidas à vontade desde o primeiro dia. As rações utilizadas foram isonutritivas, com exceção dos minerais em estudo. Dois tipos de ração foram formulados segundo a fase de criação: inicial de 0 a 21 dias e final de 21 a 42 dias.

Aos 21 e 42 dias de idade, duas aves por parcela experimental foram selecionadas para serem abatidas, das quais procedeu-se à retirada da tíbia esquerda. Para sua obtenção, as coxas foram descarnadas com auxílio de uma faca, identificadas com anilha de alumínio e armazenadas em congelador.

Os tratamentos foram constituídos por uma dieta testemunha, formulada à base de milho, farelo de soja, minerais e vitaminas, visando atender todas as exigências nutricionais por fase de criação, segundo Rostagno et al. (1994). As dietas dos demais tratamentos foram formuladas à base de milho, farelo de soja e $15 \%$ de farelo de arroz integral, com baixo fósforo disponível e sem suplementação de ferro, cobre, zinco e manganês. A cada tratamento utilizou-se uma combinação das enzimas em estudo. Em substituição ao premix mineral, responsável pelo fornecimento dos microminerais, utilizou-se apenas o iodo, na forma de iodato de cálcio ( $63 \%$ de iodo), na proporção de 0,33 g por tonelada de ração. Para o fósforo disponível, o nível utilizado foi de, aproximadamente, $40 \%$ do recomendado por Rostagno et al. (1994), ou seja, $0,18 \%$ de $\mathrm{P}$ disponível na fase inicial e $0,16 \%$ de $\mathrm{P}$ disponível na fase final de criação.

A enzima com atividade xilanase utilizada foi da marca comercial Avizyme 1300, produzida pela Finnfeeds International e fornecida pela Nutron Alimentos, na dosagem recomendada pelo fabricante $(1,0 \mathrm{~kg} / \mathrm{t}$ de ração). A enzima fitase utilizada no experimento foi da marca comercial Natuphos, produzida e fornecida pela BASF. Trata-se de uma marca registrada de fitase obtida pela fermentação 
por meio de fungos do grupo Aspergillus niger, que contém atividade inicial mínima, declarada pelo fabricante, de $5000 \mathrm{FTU} / \mathrm{g}$. Uma unidade de fitase (FTU) é definida como sendo a quantidade de enzima necessária para liberar um micromol de fósforo inorgânico em um minuto num substrato de sódiofitato, à temperatura de $37^{\circ} \mathrm{C}$ e $\mathrm{pH} 5,5$.

Os tratamentos ficaram assim constituídos:

1. dieta prática, sem FAI e sem enzimas

2. dieta com $15 \%$ de FAI, com baixo fósforo disponível, sem suplementação de $\mathrm{Mn}, \mathrm{Zn}, \mathrm{Fe}$ e Cu, sem adição de enzimas

3. tratamento $2+$ xilanase

4. tratamento $2+400 \mathrm{FTU} / \mathrm{kg}$

5. tratamento $2+400 \mathrm{FTU} / \mathrm{kg}+$ xilanase

6. tratamento $2+800 \mathrm{FTU} / \mathrm{kg}$

7. tratamento $2+800 \mathrm{FTU} / \mathrm{kg}+$ xilanase

8. tratamento $2+1.200 \mathrm{FTU} / \mathrm{kg}$

9. tratamento $2+1.200 \mathrm{FTU} / \mathrm{kg}+$ xilanase

A formulação e a composição das dietas experimentais, segundo a fase de criação, encontram-se na Tabela 1.

O peso vivo foi determinado pela pesagem de todas as aves das unidades experimentais. $O$ consumo de ração foi calculado pela diferença entre a pesagem da ração fornecida e a sobra nos comedouros das unidades experimentais. A conversão alimentar foi calculada dividindo-se o consumo de ração acumulado pelo peso das aves. As tíbias, após retiradas do congelador, foram fervidas em panela de alumínio por 15 minutos para retirada dos resíduos de carne, cartilagem proximal e fíbula. Em seguida, foram lavadas em água fria para completar a retirada dos resíduos. Após a limpeza, as tíbias foram secas em estufa a temperatura de $100^{\circ} \mathrm{C}$ por 24 horas e, em seguida, desengorduradas. Após desengorduramento, foram processadas em moinho tipo "Willey" e armazenadas em sacos plásticos devidamente identificados. Após, procedeu-se à determinação de cinzas, fósforo, ferro, cobre, zinco e manganês.

As cinzas foram determinadas conforme metodologia de Silva (1990). A solução mineral foi preparada utilizando-se os procedimentos da via úmida. Da solução mineral determinou-se o P pelo método colorimétrico, utilizando-se vanadato-molibdato e a leitura realizada em colorímetro. As determinações de $\mathrm{Fe}, \mathrm{Cu}, \mathrm{Zn}$ e $\mathrm{Mn}$ foram realizadas por espectrofotometria de absorção atômica em aparelho da marca Varian-Spectr AA-100.

O delineamento experimental utilizado foi o inteiramente casualizado. Os dados foram analisados estatisticamente, em esquema fatorial $4 \times 2$ (quatro

Tabela 1 - Composição das dietas experimentais

Table 1 - Composition of the experimental diets

\begin{tabular}{|c|c|c|c|c|}
\hline \multirow{2}{*}{$\begin{array}{l}\text { Ingredientes }(\mathrm{kg}) \\
\text { Ingredient }\end{array}$} & \multicolumn{2}{|c|}{$0-21$ dias } & \multicolumn{2}{|c|}{$21-42$ dias } \\
\hline & $\mathrm{T} 1$ & T2 a T9 & $\mathrm{T} 1$ & T2 a T9 \\
\hline Milho (Corn) & 60,240 & 46,860 & 63,500 & 50,000 \\
\hline Farelo de soja (Soybean meal) & 34,840 & 32,360 & 30,270 & 27,790 \\
\hline Farelo de arroz integral (Whole rice bran) & - & 15,000 & - & 15,000 \\
\hline Óleo de soja (Soybean oil) & 1,104 & 2,540 & 2,730 & 4,220 \\
\hline Fosfato bicálcico (Dicalcium phosphate) & 1,850 & 0,260 & 1,600 & 0,180 \\
\hline Calcário (Limestone) & 1,166 & 2,106 & 1,150 & 1,986 \\
\hline Sal iodado (Iodized salt) & 0,350 & 0,350 & 0,300 & 0,300 \\
\hline Suplemento vitamínico (Vitamin supplement) & $0,400^{1}$ & 0,400 & $0,400^{2}$ & 0,400 \\
\hline Suplemento mineral (Mineral supplement) & 0,050 & - & 0,050 & - \\
\hline Enzimas + inerte $($ Enzyme + inert $)$ & - & 0,124 & - & 0,124 \\
\hline \multicolumn{5}{|l|}{$\begin{array}{l}\text { Composição - valores calculados } \\
\text { Composition - calculated values }\end{array}$} \\
\hline Energia metabolizável (kcal/kg) (Metabolizable energy) & 2.900 & 2.900 & 3.050 & 3.050 \\
\hline Proteína bruta (\%) (Crude protein) & 20,50 & 20,50 & 18,70 & 18,70 \\
\hline Fósforo total (\%) (Total phophorus) & 0,70 & 0,58 & 0,63 & 0,55 \\
\hline Fósforo disponível (\%) (Available phosphorus) & 0,45 & 0,18 & 0,40 & 0,16 \\
\hline Cálcio (\%) (Calcium) & 0,98 & 0,98 & 0,90 & 0,90 \\
\hline Manganês (ppm) (Manganese, \%) & 93,9 & 23,4 & 91,9 & 21,8 \\
\hline Ferro (ppm) (Iron, \%) & 104,3 & 57,3 & 102,2 & 55,3 \\
\hline Cobre (ppm) (Copper, \%) & 12,3 & 4,5 & 11,9 & 4,2 \\
\hline Zinco $(\mathrm{ppm})($ Zinc, \%) & 73,7 & 25,4 & 72,3 & 24,1 \\
\hline
\end{tabular}

R. Bras. Zootec., v.32, n.5, p.1147-1156, 2003 
níveis de fitase $\mathrm{x}$ dois níveis de xilanase) mais um tratamento adicional (testemunha). Para as análises, utilizou-se o pacote computacional SAEG (Sistema para Análises Estatísticas e Genéticas), segundo Euclydes (1989). Quando a análise de variância mostrou efeitos significativos para os níveis de fitase, realizou-se a sua decomposição em polinômios ortogonais. Para comparação dos tratamentos com o tratamento testemunha, utilizou-se o teste de Dunnett, segundo Pimentel Gomes (1970), realizado pelo programa computacional SANEST, segundo Sarries, Alves e Oliveira (1992).

\section{Resultados e Discussão}

Os valores médios de peso vivo, consumo de ração e conversão alimentar das aves, aos 21 dias de idade, são apresentados na Tabela 2. Em nenhum parâmetro avaliado houve interação significativa entre a enzima fitase e a enzima xilanase.

O peso vivo, o consumo de ração e a conversão alimentar foram afetados significativamente $(\mathrm{P}<0,05)$ pelo nível de fitase da dieta. O detalhamento da análise de variância por meio de regressão polinomial mostrou efeito quadrático para peso vivo e consumo de ração, enquanto o efeito da fitase sobre a conversão alimentar foi descrito por uma equação linear. Pela derivação da equação de regressão para peso vivo, determinou-se o melhor nível de enzima, sendo de 1105 unidades/kg para $640 \mathrm{~g}$ de peso vivo, $947 \mathrm{~g}$ de consumo de ração e conversão alimentar de 1,48.

A utilização da enzima xilanase não afetou de maneira significativa $(\mathrm{P}>0,05)$ o peso vivo e o consumo de ração. Entretanto, as tendências de maior peso vivo e menor consumo de ração proporcionaram conversão alimentar significativamente melhor $(\mathrm{P}<0,05)$ com a utilização de xilanase na dieta.

O efeito da xilanase sobre a conversão alimentar, possivelmente confirma a sua ação sobre a digestibilidade de nutrientes, principalmente no aumento da energia metabolizável. A análise dos dados mostra que, com a utilização de xilanase, embora não significativo, o peso vivo foi $2,1 \%$ superior e o consumo de ração, $4,1 \%$ inferior, quando comparados às dietas sem xilanase. Isto resultou em conversão alimentar $5,8 \%$ melhor, estatisticamente significativa.

Tabela 2 -Desempenho dos frangos de corte aos 21 dias de idade

Table 2 - Performance of broiler chicks at 21 days of age

\begin{tabular}{|c|c|c|c|}
\hline $\begin{array}{l}\text { Dietas } \\
\text { Diets }\end{array}$ & $\begin{array}{l}\text { Peso vivo }(\mathrm{g})^{1} \\
\text { Live weight }(g)\end{array}$ & $\begin{array}{c}\text { Consumo de ração }(\mathrm{g})^{2} \\
\text { Feed intake }(\mathrm{g})\end{array}$ & $\begin{array}{c}\text { Conversão alimentar }{ }^{3}(\mathrm{~g}: \mathrm{g}) \\
\text { Feed:gain ratio }(\mathrm{g}: \mathrm{g})\end{array}$ \\
\hline Dieta controle & 689 & 982 & 1,42 \\
\hline \multicolumn{4}{|l|}{ Control diet } \\
\hline \multicolumn{4}{|l|}{ Fitase (FTU/kg) } \\
\hline \multicolumn{4}{|l|}{ Phytase (FTU/kg) } \\
\hline 0 & $519 *$ & $818 *$ & $1,57 *$ \\
\hline 400 & $588 *$ & $886^{*}$ & $1,50 *$ \\
\hline 800 & 629 & 945 & $1,50^{*}$ \\
\hline 1.200 & 629 & 932 & $1,48^{*}$ \\
\hline \multicolumn{4}{|l|}{ Xilanase $(1 \mathrm{~kg} / \mathrm{t})$} \\
\hline \multicolumn{4}{|l|}{ Xylasase $(1 \mathrm{~kg} / \mathrm{t})$} \\
\hline Sem & $585 a$ & $914 a$ & $1,56 \mathrm{a}$ \\
\hline Without & & & \\
\hline Com & $598 \mathrm{a}$ & $877 \mathrm{a}$ & $1,47 b$ \\
\hline With & & & \\
\hline Fitase x xilanase & $\mathrm{ns}$ & $\mathrm{ns}$ & $\mathrm{ns}$ \\
\hline \multicolumn{4}{|l|}{ Phytase $x$ xylanase } \\
\hline Média & 591 & 895 & 1,51 \\
\hline \multicolumn{4}{|l|}{ Mean } \\
\hline CV $(\%)$ & 6,85 & 7,58 & 4,71 \\
\hline
\end{tabular}

* Diferem da testemunha $(P<0,05)$ pelo teste de Dunnett (Differ from control $[P<.05]$ by Dunnett test).

Médias com letras diferentes na mesma coluna e fonte de variação, diferem pelo teste $F(P<0,05)$.

Means with different letters in the same column and variation source, differ by $F$ test $(P<.05)$.

$\mathrm{ns}=$ não significativo (not significant).

1 Efeito quadrático para nível de fitase (Quadratic effect for phytase level) $Y=518,8+0,221 X-0,0001 X^{2}\left(R^{2}=0,99\right)$.

2 Efeito quadrático para nível de fitase (Quadratic effect for phytase level) $Y=815,2+0,252 X-0,00012 X^{2}\left(R^{2}=0,97\right)$.

3 Efeito linear para nível de fitase (Linear effect for phytase level) $Y=1,558-0,000069 \times\left(R^{2}=0,808\right)$. 
A melhor conversão alimentar apresentada pelas aves que receberam xilanase acarretou incremento na energia metabolizável da dieta, já que os pesos obtidos foram semelhantes. Portanto, para ocorrer melhor conversão alimentar, seguramente, o consumo de ração deve ter sido menor, embora na análise estatística isto não tenha ficado confirmado a $5 \%$ de significância, nível adotado neste trabalho.

Pack \& Bedford (1997) apresentaram um resumo dos resultados de desempenho de 51 ensaios com frangos de corte, alimentados com dietas a base de milho e farelo de soja, ou sorgo e farelo de soja, suplementadas com um complexo enzimático, similar ao utilizado neste experimento, conduzidos em diversas instituições de pesquisa e empresas avícolas comerciais. A adição do suplemento enzimático proporcionou melhora, em média, de $2,2 \%$ no ganho de peso e $2,8 \%$ na conversão alimentar.

Zanella (1998) também utilizou um complexo enzimático similar ao deste trabalho. Dietas à base de milho e soja processada de três maneiras diferentes (farelo de soja, soja integral tostada e soja integral extrusada) foram utilizadas em frangos de corte de 1 a 45 dias de idade. A adição do complexo enzimático melhorou em $2,2 \%$ o ganho de peso, $2,04 \%$ a conversão alimentar e não houve diferença significativa no consumo de ração, em relação às dietas sem suplementação enzimática. Segundo o autor, a melhora na conversão alimentar e no ganho de peso das aves que receberam o suplemento enzimático pode ser atribuída ao aumento dos coeficientes de digestibilidade dos nutrientes da dieta, o que também foi verificado naquele trabalho.

Ravindran et al. (1999) realizaram um experimento para avaliar o efeito das enzimas fitase e xilanase no desempenho de frangos de corte de 7 a 28 dias de idade, utilizando uma dieta com $57 \%$ de trigo. Os autores não encontraram diferenças no ganho de peso e no consumo de ração da dieta basal sem enzimas e das dietas com enzimas utilizadas individualmente ou combinadas. Entretanto, a conversão alimentar foi significativamente melhor quando foram utilizadas as duas enzimas combinadas.

Os resultados deste experimento mostram que os tratamentos com $15 \%$ de FAI, quando comparados com o tratamento testemunha, pelo teste de Dunnett, indicaram que o peso vivo e o consumo de ração foram menores $(\mathrm{P}<0,05)$ nos tratamentos com zero e $400 \mathrm{FTU} / \mathrm{kg}$. Entretanto, com a utilização de $800 \mathrm{e}$ $1.200 \mathrm{FTU} / \mathrm{kg}$, estes parâmetros não diferiram
$(\mathrm{P}>0,05)$ do tratamento testemunha, indicando que a fitase, acima de $800 \mathrm{FTU} / \mathrm{kg}$, permite a utilização de 15\% de FAI com redução simultânea da fonte de fósforo inorgânico e microminerais. Já a conversão alimentar foi pior em todos os tratamentos, independente do nível de fitase utilizado.

Os resultados obtidos no desempenho das aves aos 21 dias de idade indicam a efetiva ação da fitase no aumento da disponibilidade do fósforo, já que o nível de fósforo disponível utilizado foi de apenas $0,18 \%$, quando a recomendação é de $0,45 \%$, segundo Rostagno et al.(1994). Assim, quando níveis mais altos de fitase $(800$ e $1.200 \mathrm{FTU} / \mathrm{kg}$ ) foram adicionados à ração, o desempenho equiparou-se ao das aves que receberam dieta com $0,45 \%$ de fósforo disponível.

Os resultados do presente trabalho foram semelhantes aos obtidos por Munaro et al. (1996a), os quais, utilizando níveis de fitase em dietas com farelo de arroz, encontraram que o nível $1.000 \mathrm{FTU} / \mathrm{kg}$ proporcionou o melhor desempenho das aves aos 21 dias de idade. Teichmann et al. (1998) tambémutilizando diferentes níveis de fitase $(300,600$ e $900 \mathrm{FTU} / \mathrm{kg}) \mathrm{em}$ dieta com $15 \%$ de farelo de arroz, encontraram resposta linear para ganho de peso e consumo de ração, indicando que o melhor nível de fitase para dietas com $15 \%$ de farelo de arroz está acima do máximo utilizado naquele trabalho, de $900 \mathrm{FTU} / \mathrm{kg}$.

Diversos autores demonstraram que o efeito da fitase sobre a disponibilidade do fósforo fitico é descrito por equações não lineares, ou seja, a quantidade de fósforo liberado por unidade de fitase decresce com o aumento de fitase na dieta. Denbow et al.(1995) concluiu, por meio de equações não lineares, que um nível de $821 \mathrm{FTU} / \mathrm{kg}$ proporcionou o melhor desempenho em frangos de corte, utilizando dietas à base de milho e farelo de soja. Yi et al. (1996) obtiveram melhor desempenho das aves com um nível de $785 \mathrm{FTU} / \mathrm{kg}$, em frangos de 21 dias de idade, utilizando dietas à base de milho e farelo de soja e $0,27 \%$ de fósforo disponível. Kornegay et al. (1996), utilizando níveis de zero a $1.200 \mathrm{FTU} / \mathrm{kg}$ em dietas à base de milho e farelo de soja e 0,20 ou $0,27 \%$ de fósforo disponível, determinou por meio de derivações das equações, que $939 \mathrm{FTU} / \mathrm{kg}$ propiciaram o melhor desempenho das aves aos 21 dias de idade.

Parece ficar claro que, em dietas à base de milho e farelo de soja, os níveis de fitase necessários para o melhor desempenho são menores do que quando se utiliza o farelo de arroz. Isto é perfeitamente justificável, já que a porcentagem de fósforo total do

\section{R. Bras. Zootec., v.32, n.5, p.1147-1156, 2003}


farelo de arroz é bastante alto e, deste, a maior parte está complexada na molécula de fitato. Assim, há maior necessidade de fitase para hidrolisar o fósforo fítico, permitindo, por outro lado, a utilização de níveis menores de fósforo disponível, pois a quantidade de fósforo total é razoavelmente alta.

Os valores médios de peso vivo, consumo de ração e conversão alimentar dos frangos de corte aos 42 dias de idade encontram-se na Tabela 3. Os resultados foram bastante semelhantes aos obtidos aos 21 dias de idade, exceto para conversão alimentar.

Não houve, em nenhum parâmetro avaliado, interação significativa $(\mathrm{P}>0,05)$ entre as enzimas fitase e xilanase.

O nível de fitase utilizado afetou de maneira significativa $(\mathrm{P}<0,05)$ o peso vivo, o consumo de ração e a conversão alimentar. O detalhamento da análise de variância por meio de regressão polinomial mostrou que o efeito da fitase sobre o peso vivo e o consumo de ração foi descrito por uma equação quadrática, enquanto que, para conversão alimentar, o efeito foi linear. Pela derivação da equação de regressão determinou-se o nível de fitase para proporcionar o melhor peso vivo, sendo de 1.023 $\mathrm{FTU} / \mathrm{kg}$, para um peso vivo de $2.094 \mathrm{~g}$, consumo de ração de $3.788 \mathrm{~g}$ e conversão alimentar de 1,81 .

A utilização da enzima xilanase não afetou de maneira significativa $(\mathrm{P}>0,05)$ o peso vivo e o consumo de ração. Entretanto, há tendência a menor consumo de ração nos tratamentos com xilanase, resultando em efeito significativo $(\mathrm{P}<0,05)$ na conversão alimentar, permitindo redução de $2,1 \%$ no consumo de ração e melhora de $2,1 \%$ na conversão alimentar, enquanto o peso vivo foi similar.

A diferença na conversão alimentar, embora significativa, não foi tão expressiva quanto a encontrada aos 21 dias de idade. Isto certamente se justifica pela maior eficiência das enzimas carboidrases na fase inicial das aves, o que é confirmado por Campbell \& Bedford (1992). Segundo Brenes et al. (1996), durante as primeiras semanas de vida, a atividade enzimática e o desenvolvimento fisiológico das aves não estão totalmente consolidados. Segundo o autor, a digestibilidade da energia é significativamente inferior em aves até três semanas de idade e os efeitos negativos dos polissacarídeos

Tabela 3 - Desempenho dos frangos de corte aos 42 dias de idade Table 3 - Performance of broiler chicks at 42 days of age

\begin{tabular}{|c|c|c|c|}
\hline $\begin{array}{l}\text { Dietas } \\
\text { Diets }\end{array}$ & $\begin{array}{l}\text { Peso vivo }(\mathrm{g})^{1} \\
\text { Live weight }(g)\end{array}$ & $\begin{array}{l}\text { Consumo de ração }(\mathrm{g})^{2} \\
\text { Feed intake }(g)\end{array}$ & $\begin{array}{l}\text { Conversão alimentar }{ }^{3}(\mathrm{~g}: \mathrm{g}) \\
\text { Feed:gain ratio }(\mathrm{g}: \mathrm{g})\end{array}$ \\
\hline Dieta controle & 2181 & 4094 & 1,87 \\
\hline \multirow{2}{*}{\multicolumn{4}{|c|}{$\begin{array}{l}\text { Control diet } \\
\text { Fitase (FTU/kg) }\end{array}$}} \\
\hline \multirow{2}{*}{\multicolumn{4}{|c|}{ Phytase (FTU/kg) }} \\
\hline & & & \\
\hline 0 & $1668^{*}$ & $3129 *$ & $1,92^{*}$ \\
\hline 400 & $1975^{*}$ & 3729 & 1,88 \\
\hline 800 & 2025 & 3716 & $1,83^{*}$ \\
\hline 1.200 & 2097 & 3836 & $1,83^{*}$ \\
\hline \multicolumn{4}{|l|}{ Xilanase $(1 \mathrm{~kg} / \mathrm{t})$} \\
\hline \multicolumn{4}{|l|}{ Xylanase $(1 \mathrm{~kg} / \mathrm{t})$} \\
\hline \multicolumn{4}{|l|}{ Sem } \\
\hline Without & 1931a & $3641 \mathrm{a}$ & $1,88 \mathrm{a}$ \\
\hline Com & 1931a & $3564 a$ & $1,84 \mathrm{~b}$ \\
\hline \multicolumn{4}{|l|}{ With } \\
\hline Fitase $\mathrm{x}$ xilanase & $\mathrm{ns}$ & $\mathrm{ns}$ & $\mathrm{ns}$ \\
\hline \multicolumn{4}{|l|}{ Phytase $x$ xylanase } \\
\hline Média & 1931 & 3602 & 1,86 \\
\hline \multicolumn{4}{|l|}{ Mean } \\
\hline CV $(\%)$ & 6,27 & 5,98 & 2,29 \\
\hline
\end{tabular}

* Diferem da testemunha $(P<0,05)$ pelo teste de Dunnett (Differ from control $[P<.05]$ by Dunnett test).

Médias com letras diferentes na mesma coluna e fonte de variação, diferem pelo teste $F(P<0,05)$.

Means with different letters in the same column and variation source, differ by $F$ test $(P<.05)$.

ns = não significativo (not significant).

1 Efeito quadrático para nível de fitase (Quadratic effect for phytase level) $Y=1644+0,879 X-0,0043 X^{2}\left(R^{2}=0,961\right)$.

2 Efeito quadrático para nível de fitase (Quadratic effect for phytase level) $Y=3166+1,427 X-0,00075 X^{2}\left(R^{2}=0,91\right)$.

3 Efeito linear para nível de fitase (Linear effect for phytase level) $Y=1,918-0,000082 \times\left(R^{2}=0,927\right)$. 
não amiláceos são muito mais evidentes nesta idade. Assim, a utilização de suplementos enzimáticos é muito mais justificada e tem efeitos muito mais expressivos em frangos jovens do que em adultos e em galinhas poedeiras.

Zanella (1998), em trabalho realizado com frangos de 1 a 45 dias com rações à base de milho e sojas processadas, analisando o período total de criação obteve aumento de $2,2 \%$ no ganho de peso e melhora de 2,04\% na conversão alimentar, sem efeito no consumo de ração. Entretanto, quando analisou os resultados semanalmente, não obteve efeito do uso do complexo enzimático na fase de 38 a 45 dias em nenhum parâmetro avaliado. As diferenças foram observadas nos períodos iniciais compreendidos entre 1 e 21 dias e 22 e 35 dias.

A comparação dos resultados com o tratamento testemunha, pelo teste de Dunnett, mostra que o peso vivo foi semelhante à testemunha quando foram utilizadas 800 e $1.200 \mathrm{FTU} / \mathrm{kg}$. Os níveis de zero e 400 FTU/kg apresentaram pesos significativamente menores. Para consumo de ração, os níveis de 400, 800 e $1.200 \mathrm{FTU} / \mathrm{kg}$ foram estatisticamente iguais à testemunha, enquanto, no nível zero, o consumo de ração foi menor. A conversão alimentar do tratamento testemunha foi igual à utilização de $400 \mathrm{FTU} / \mathrm{kg}$, entretanto, menor que o nível zero e maior que os níveis de 800 e $1.200 \mathrm{FTU} / \mathrm{kg}$.

Os valores médios dos teores de cinza, fósforo, zinco, ferro, manganês e cobre nas tíbias dos frangos de corte aos 21 e 42 dias de idade estão nas Tabelas 4 e 5 , respectivamente.

Em nenhum parâmetro avaliado houve interação significativa $\mathrm{P}(>0,05)$ entre as enzimas fitase e xilanase. A utilização da enzima xilanase não afetou significativamente $(\mathrm{P}>0,05)$ o teor de cinzas e deposição dos minerais estudados nas tíbias das aves.

Vários autores, entre eles Fialho (1991), Teixeira (1994) e Domene (1996), relacionam a presença de fibra no alimento e a conseqüente formação de gel, como um dos fatores que afetam negativamente a absorção de minerais, entre outros nutrientes. A utilização de uma enzima carboidrase, com capacidade para reduzir a viscosidade da digesta, poderia aumentar a digestibilidade de nutrientes, entre eles os minerais. A deposição de microminerais no osso parece não ser o melhor critério de resposta para avaliar a sua absorção, embora, para o manganês, Fialho (1991)

Tabela 4 - Cinza, fósforo e microminerais na tíbia dos frangos de corte aos 21 dias Table 4 - Ash, phophorus and microminerals in the tibia of broiler chicken at 21 days

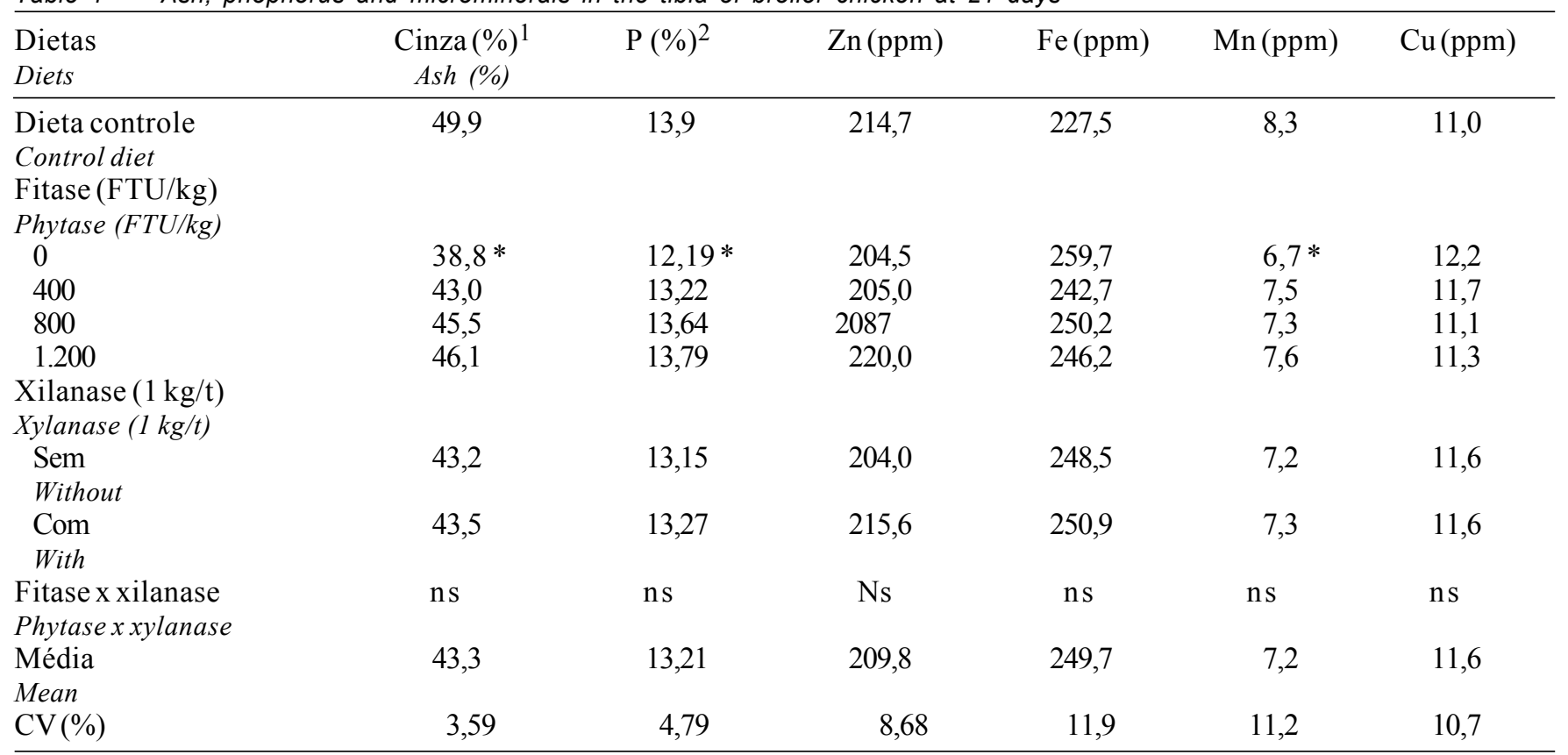

* Diferem da testemunha $(P<0,05)$ pelo teste Dunnett (Differ from control $[P<.05]$ by Dunnett test). ns = não-significativo (not significant).

1 Efeito linear para nível de fitase (Linear effect for phytase levels) $Y=39,73+0,0061 \times\left(R^{2}=0,90\right)$.

2 Efeito linear para nível de fitase (Linear effect for phytase levels) $Y=12,43+0,0013 \times\left(R^{2}=0,87\right)$. 
Tabela 5 - Cinza, fósforo e microminerais na tíbia dos frangos de corte aos 42 dias

Table 5 - Ash, phophorus and microminerals in the tibia of broiler chicken at 42 days

\begin{tabular}{|c|c|c|c|c|c|c|}
\hline $\begin{array}{l}\text { Dietas } \\
\text { Diets }\end{array}$ & $\begin{array}{c}\text { Cinza }(\%)^{1} \\
\text { Ash (\%) }\end{array}$ & $\mathrm{P}(\%)^{2}$ & $\mathrm{Zn}(\mathrm{ppm})$ & $\mathrm{Fe}(\mathrm{ppm})$ & $\mathrm{Mn}(\mathrm{ppm})$ & $\mathrm{Cu}(\mathrm{ppm})$ \\
\hline $\begin{array}{l}\text { Dieta controle } \\
\text { Control diets } \\
\text { Fitase (FTU } / \mathrm{kg})\end{array}$ & 48,6 & 15,2 & 137,0 & 278,7 & 7,6 & 10,0 \\
\hline Phytase (FTU/kg) & & & & & & \\
\hline $\begin{array}{l}0 \\
400\end{array}$ & $\begin{array}{l}44,4 * \\
46,0 *\end{array}$ & $\begin{array}{l}13,7 * \\
14,3 *\end{array}$ & $\begin{array}{l}127,1 \\
136,1\end{array}$ & $\begin{array}{l}274,6 \\
268,0\end{array}$ & $\begin{array}{l}7,2 \\
7,3\end{array}$ & $\begin{array}{l}10,3 \\
10,9\end{array}$ \\
\hline 800 & 47,0 & 14,6 & 132,5 & 254,5 & 7,1 & 10,6 \\
\hline 1.200 & 48,3 & 15,4 & 132,3 & 260,2 & 7,4 & 11,3 \\
\hline Xilanase $(1 \mathrm{~kg} / \mathrm{t})$ & & & & & & \\
\hline $\begin{array}{l}\text { Xylanase }(1 \mathrm{~kg} / \mathrm{t}) \\
\text { Sem }\end{array}$ & & & & & & \\
\hline $\begin{array}{l}\text { Without } \\
\text { Com }\end{array}$ & 46,0 & 14,5 & 131,8 & 258,8 & 7,1 & 10,6 \\
\hline With & 46,6 & 14,5 & 132,1 & 269,8 & 7,4 & 10,9 \\
\hline $\begin{array}{l}\text { Fitase } \mathrm{x} \text { xilanase } \\
\text { Phytase } x \text { xylanase }\end{array}$ & $\mathrm{ns}$ & $\mathrm{ns}$ & $\mathrm{ns}$ & $\mathrm{ns}$ & $\mathrm{ns}$ & $\mathrm{ns}$ \\
\hline $\begin{array}{l}\text { Média } \\
\text { Mean }\end{array}$ & 46,3 & 14,5 & 131,9 & 264,3 & 7,2 & 10,7 \\
\hline CV $(\%)$ & 3,52 & 7,52 & 5,36 & 13,7 & 8,83 & 15,3 \\
\hline
\end{tabular}

* Diferem da testemunha $(P<0,05)$ pelo teste Dunnett (Differ from control $[P<.05]$ by Dunnett test). ns = não significativo (not significant).

${ }^{1}$ Efeito linear para nível de fitase (Linear effect for phytase levels) $Y=44,52+0,00319 X\left(R^{2}=0,99\right)$.

2 Efeito linear para nível de fitase (Linear effect for phytase levels) $Y=13,73+0,00137 X\left(R^{2}=0,97\right)$.

cite que a deposição no osso seja o critério de resposta mais preciso para avaliar a sua biodisponibilidade. Para o zinco, o ferro e o cobre, diferenças na absorção poderiam ser mais facilmente detectadas no fígado, que é o mais importante órgão de reserva destes minerais (Georgievskii, 1982; Teixeira, 1994; Mamani, 1996).

A utilização de níveis de fitase também não afetou a deposição de zinco, ferro, cobre e manganês no osso dos frangos de corte aos 21 e aos 42 dias de idade.

A comparação entre os tratamentos que não foram suplementados com fonte inorgânica dos microminerais em estudo com o tratamento testemunha que recebeu suplementação mostrou não haver nenhuma diferença significativa na concentração destes minerais. Tal fato indica que o mecanismo homeostático da ave é bastante eficiente, possivelmente aumentando a absorção e reduzindo a excreção endógena, sem afetar de maneira significativa a concentração nos ossos.

Sebastian et al. (1996b), utilizando dietas normais ou com baixo fósforo disponível, suplementadas ou não com $600 \mathrm{FTU} / \mathrm{kg}$, embora tenham encontrado efeito significativo da fitase na taxa de retenção de fósforo, cálcio, cobre e zinco, não encontraram diferenças na concentração de cobre e zinco na tíbia. A concentração de fósforo e cálcio aumentou quando a dieta de baixo fósforo foi suplementada com fitase. Sebastian et al. (1996a) também obtiveram resultados semelhantes, não encontrando diferenças significativas na concentração de zinco, cobre e manganês na tíbia, quando suplementaram as dietas com $600 \mathrm{FTU} / \mathrm{kg}$. Entretanto, encontraram diferença significativa para a concentração de ferro no osso.

Resultados contrários aos do presente trabalho foram obtidos por Roberson e Edwards Jr. (1994), que encontraram diferença significativa na deposição de zinco nas tíbias de frangos em dietas à base de milho e farelo de soja, com $600 \mathrm{FTU} / \mathrm{kg}$, quando comparada com nível zero de fitase. Biehl et al. (1995), também utilizando dietas à base de milho e farelo de soja, obtiveram incrementos significativos na concentração de zinco e manganês no osso, com a utilização de $1.200 \mathrm{FTU} / \mathrm{kg}$, em relação à dieta sem suplementação destes minerais.

Tais resultados, adversos aos obtidos no presente trabalho, podem ser atribuídos, possivelmente, ao tipo de dieta utilizada. Na maioria dos trabalhos em que 
foram observadas diferenças na deposição de microminerais no osso, as dietas eram constituídas à base de milho e farelo de soja. A composição destes microminerais no milho e farelo de soja é bastante baixa, proporcionando deficiência severa. No presente trabalho, ao ser utilizada uma dieta com $15 \%$ de farelo de arroz, o nível dos microminerais tornou-se bastante elevado, devido a composição do farelo de arroz. A quantidade fornecida, se considerarmos os microminerais do vegetais como totalmente disponíveis, tornou-se superior à exigência das aves. Por isso, é possível que, mesmo sem a suplementação de microminerais inorgânicos, o aumento na taxa de absorção promovido, em parte, pela alteração do mecanismo de absorção da ave, a quantidade fornecida tenha se tornado suficiente para atender às suas exigências. Assim, o efeito da fitase na deposição dos microminerais no osso não propiciou efeitos significativos, já que, mesmo sem fitase, a quantidade necessária já teria sido absorvida e o osso já estaria com a sua concentração adequada.

A porcentagem de cinza e fósforo das tíbias dos frangos de corte aos 21 e 42 dias de idade foi afetada pelos níveis de fitase utilizado. O detalhamento da análise de variância, por meio de regressão polinomial, mostrou efeito linear, tanto para cinza quanto para fósforo na tíbia, nas duas idades estudadas.

Muitos autores indicam a porcentagem de cinza e fósforo no osso como a principal medida de resposta para avaliar a disponibilidade do fósforo, pois refletem melhor as variações do mineral na dieta (Zhang, 1997; Ravindran et al., 1995; Teichmann, López \& Lópes, 1998).

Os resultados do presente trabalho indicam, portanto, o evidente efeito da fitase sobre a disponibilidade do fósforo fítico. Resultados semelhantes, com relação à porcentagem de cinza e fósforo na tíbia, foram apresentados por Munaro et al. (1996b), Teichmann et al. (1998), Dembow et al. (1995), Kornegay et al. (1996) e Pizzolante (2000).

\section{Conclusões}

A utilização de fitase em dietas com $15 \%$ de FAI permite redução na suplementação inorgânica de fósforo, ferro, cobre, zinco e manganês, sem afetar o desempenho das aves.

A fitase aumenta o teor de cinzas e fósforo na tíbia, porém não afeta a deposição de $\mathrm{Fe}, \mathrm{Cu}, \mathrm{Zn}$ e $\mathrm{Mn}$.

A utilização da enzima xilanase melhora a conversão alimentar das aves.

R. Bras. Zootec., v.32, n.5, p.1147-1156, 2003

\section{Literatura Citada}

BIEHL, R.R.; BAKER, D.H.; DeLUCA, H.F. 1a-Hydroxylated cholecalciferol compounds act additively with microbial phytase to improve phosphorus, zinc and manganese utilization in chicks fed soy-based diets. Journal of Nutrition, v.125, n.9, p.2407-2416, 1995.

BRENES, A.; LÁZARO, R.; GARCÍA, M. et al. Utilizacion pratica de compejos enzimaticos en avicultura. In: Avances en nutrición y alimentación animal. Madrid: Fundacion Española para el desarollo de la nutrición animal, 1996. p.135-157. (Curso de Especialización, 12)

CAMPBELL, G.L.; BEDFORD, M.R. Enzyme apllications for monogastric feeds: A review. Canadian Journal of Animal Science, v.72, n.2, p.449-466, 1992.

DEMBOW, D.M.; RAVINDRAN, V.; KORNEGAY, et al. Improving phosphorus availability in soybean meal for broilers by supplemental fitase. Poultry Science, v.74, n.11, p.18311842, 1995.

DOMENE, S.M.A. Estudo do valor nutritivo mineral do farelo de arroz. Utilização do zinco, ferro, cobre e cálcio pelo rato em crescimento. Campinas: Universidade de Campinas, 1996. 104p. Tese (Doutorado em Ciência da Nutrição) - Universidade de Campinas, 1996.

EUCLIDES, R.F. Manual de utilização do programa SAEG (Sistema para Análises Estatísticas e Genéticas). Viçosa, MG: Universidade Federal de Viçosa, 1983. 59p.

FIALHO, F.B. Disponibilidade de manganês do farelo de arroz para frangos de corte. Porto Alegre: Universidade Federal do Rio Grande do Sul, 1991. 156p. Dissertação (Mestrado em Nutrição Animal) - Universidade Federal do Rio Grande do Sul, 1991.

GEORGIEVSKII, V.I. The physiological role of macroelements. In: GEORGIEVSKII, V.I.; ANNENKOW, B.N.; SAMOKHIN, V.T. (Eds.) Mineral nutrition of animals. London: Butterworths, 1982. p.91-170.

KORNEGAY, E.T.; DENBOW, D.M.; YI, Z. et al. Response of broilers to graded levels of microbial phytase added to maize-soyabean-meal-based diets containing three levels of non-phytate phosphorus. British Journal Nutrition, v.75, n.4, p.839-852, 1996.

MAMANI, N.J.P. Efeito da suplementação de altos níveis dietéticos de cobre ezinco no desempenho de leitões. Piracicaba: Escola Superior de Agricultura "Luiz de Queiroz", 1996. 62p. Dissertação (Mestrado em Ciência Animal e Pastagem) - Escola Superior de Agricultura "Luiz de Queiroz", 1996.

MUNARO, F.A.; LÓPEZ, J.; LÓPEZ, S.E. et al. Efeito da fitase na biodisponibilidade do fósforo em rações com farelo de arroz desengordurado para frangos de corte. Revista da Sociedade Brasileira de Zootecnia, v.25, n.5, p.932-943, 1996 a.

MUNARO, F.A.; LÓPEZ, J.; TEIXEIRA, A.S. et al. Efeito da fitase em rações com $15 \%$ de farelo de arroz desengordurado no desempenho de frangos de corte. Revista da Sociedade Brasileira de Zootecnia, v.25, n.5, p.910-920, 1996 b.

PACK, M.; BEDFORD, M. Feed enzymes for corn-soybean broiler diets. A new concept to improve nutritional value and economics. World's Poultry Science Journal, v.13, p.87-93, 1997.

PERSSON, H.; TÜRK, M.; NYMAN, M. et al. Binding of $\mathrm{Cu}^{2+}$, $\mathrm{Zn}^{2+}$, and $\mathrm{Cd}^{2+}$ to inositol tri-, tetra-, penta-, and hexaphosphates. Journal of Agriculture of Food Chem., v.46, n.8, p.3194-3200 1998 . 
PIMENTEL GOMES, F. Curso de estatística experimental. 4.ed.Piracicaba: Escola Superior de Agricultura “LuizdeQueiroz", 1970. 430p.

PIZZOLANTE, C.C. Estabilidade da fitase e sua utilização na alimentação de frangos de corte. Lavras: Universidade Federal de Lavras, 2000. 117p. Tese (Doutorado em Nutrição de Monogástricos) - Universidade Federal de Lavras, 2000.

RAVINDRAN, V.; KORNEGAY, E.T.; POTTER, A. et al. An evaluation of various response criteria in assessing biological availability of phosphorus for broilers. Poultry Science, v.74, n.5, p.1828-1830, 1995.

RAVINDRAN, V.; SELLE, P.H.; BRYDEN, W.L. Effects of phytase suplementation, individually an in combination with glycanase, on the nutritive value of wheat and barley. Poultry Science, v.78, n.11, p.1588-1595. 1999.

ROBERSON, K.D.; EDWARDS JR., H.M. Effects os 1,25dihydroxycholecalciferol and phytase on zinc utilization in broiler chicks. Poultry Science, v.73, n.8, p.1312-1326, 1994.

ROSTAGNO, H.S. Exigências nutricionais e biodisponibilidade de fósforo para frangos de corte. In: SIMPÓSIO INTERNACIONAL SOBRE NUTRIÇÃO DE AVES, 1998, Campinas. Anais... Campinas: Colégio Brasileiro de Nutrição Animal, 1998. p.1-27.

ROSTAGNO, H.S.; SILVA, D.J.; COSTA, P.M. et al. Composição de alimentos e exigências nutricionais de aves e suínos (Tabelas Brasileiras). Viçosa, MG: Universidade Federal de Viçosa, 1994. 59p.

SARRIES, G.A.; ALVES, M.C.; OLIVEIRA, J.C.V. SANEST Sistema para análise estatística para DOS. Piracicaba: Escola Superior de Agricultura "Luiz de Queiroz", 1992. 58p. (Série Didática CIAGRI, 6)

SEBASTIAN, S.; TOUCHBURN, S.P.; CHAVEZ, E.R. et al. Efficacy of supplemental microbial phytase at different dietary calcium levels on growth performance and mineral utilization of broiler chickens. Poultry Science, v.75, n.12, p.1516-1523, 1996a.
SEBASTIAN, S.; TOUCHBURN, S.P.; CHAVEZ, E.R. et al. The effects of supplemental microbial phytase on the performance and utilization of dietary calcium, phosphorus, copper, and zinc in broiler chickens fed corn-soybeans diets. Poultry Science, v.75, n.2, p.729-736, 1996b.

SILVA, D.J. Análise de alimentos (métodos químicos e biológicos). Viçosa, MG: Universidade Federal de Viçosa, 1990. 165p.

TEICHMANN, H.F.; LÓPEZ, J.; LÓPEZ, S.E. Efeito da fitase na biodisponibilidade de fósforo em dietas com farelo de arroz integral para frangos de corte. Revista Brasileira de Zootecnia, v.27, n.2, p.338-344, 1998.

TEIXEIRA, A.S. Exigências nutricionais de zinco e sua biodisponibilidade em sulfatos e óxidos de zinco para pintos de corte. Porto Alegre: Universidade Federal do Rio Grande do Sul, 1994. 172p. Tese (Doutorado em Produção Animal) - Universidade Federal do Rio Grande do Sul, 1994.

YI, Z.; KORNEGAY, E.T.; DENBOW, D.M. Supplemental microbial phytase improves zinc utilization in broiler. Poultry Science, v.75, p.540-546, 1996.

ZANELLA, I. Suplementação enzimática em dietas à base de milho e sojas processadas sobre a digestibilidade de nutrientes e desempenho de frango de corte. Jaboticabal: Universidade Estadual Paulista, 1998. 179p. Tese (Doutorado em Produção Animal) - Universidade Estadual Paulista, 1998.

ZHANG, B.; COON, C. The relationship of various tibia bone measurements in hens. Poultry Science, v.76, n.12, p.1698$1701,1997$.

Recebido em: 15/02/02

Aceito em: 40/11/02 